\title{
KONSEP MANAJEMEN PENDIDIKAN KARAKTER DALAM MENUMBUHKAN AKHLAKUL KARIMAH DI MTS RAUDHATUL ISLAMIYAH KEMIRI
}

\author{
Asnawati \\ UIN Antasari Banjarmasin \\ *Korespodensi: asnawati2327@gmail.com
}

\begin{abstract}
ABSTRACK
This paper discusses the concept of management of character education in MTs Raudhatul Islamiyah Kemiri, the concept in question is the pattern of character growth of students with various supporting elements such as madrasa activities, rules or regulations, and content of Islamic education lessons that are applied in MTs Raudhatul Islamiyah Kemiri. In addition to these supporting elements, in order to grow the character of morality also has several strategies in supporting the achievement of character education management concepts such as: exemplary, learning, empowerment and acculturation, retention, and assessment.

At this time Character becomes important for human life, especially for the next generation of nation. Therefore character education becomes important in school. However, the achievement of character values must be applied with good management. Character education management is a planned effort to make learners recognize, care and internalize the values so that learners are able to grow its character that consists of the process of planning, organizing, implementation and supervision.
\end{abstract}

\section{ABSTRAK}

Tulisan ini membahas tentang konsep Manajemen pendidikan karakter di MTs Raudhatul Islamiyah Kemiri, konsep yang dimaksud adalah pola pertumbuhan karakter peserta didik dengan berbagai unsur pendukung seperti kegiatan-kegiatan madrasah, tata tertib atau peraturan-peraturan, serta muatan pelajaran pendidikan Islam yang diterapkan di MTs Raudhatul Islamiyah Kemiri. Selain unsur pendukung tersebut, dalam rangka menumbuhkan karakter akhlakul karimah juga mempunyai beberapa strategi didalam menunjang tercapainya konsep manajemen pendidikan karakter seperti: keteladanan, pembelajaran, pemberdayaan dan pembudayaan, pengatan, dan penilaian.

Pada saat ini Karakter menjadi penting bagi kehidupan manusia, khususnya untuk generasi penerus bangsa. Maka dari itu pendidikan karakter menjadi penting di sekolah. Namun pencapaian nilai karakter harus diterapkan dengan manajemen yang baik. Manajemen pendidikan karakter yaitu usaha yang terencana untuk menjadikan peserta didik mengenal, peduli dan menginternalisasi nilai-nilai agar peserta didik mampu menumbuhkan karakter khasnya yang terdiri dari proses perencanaan, pengorganisasian, pelaksanaan dan pengawasan.

Keyword: Education management, character education, akhlakul karimah

\section{PENDAHULUAN}

Manajemen berasal dari bahasa latin yaitu berasal dari kata "manus" yang berarti tangan dan "agere" yang berarti melakukan. Dalam bahas inggris dikenal dengan kata manage yang berarti mengurus, mengatur, melaksanakan dan mengelola. Manajemen adalah seni yang 
mengatur proses pemanfaatan sumber daya manusia secara efektif dengan didukung oleh sumber-sumber lainnya dalam organisasi untuk mencapai tujuan (Subaidi, 2019).

Pendidikan merupakan usaha sadar yang sistematis untuk mencapai taraf hidup atau untuk mencapai kemajuan yang lebih baik. Pendidikan adalah proses bagi peserta didik untuk dapat memahami dan mengerti sesuatu hal dan mampu membuat manusia berfikir secara kritis (Agus \& Ummah, 2019). Pendidikan dianggap mampu menciptakan karakter seseorang sehingga memiliki pandangan yang luas untuk mencapai cita-cita (Wahid, Muali, \& Rafikah, 2018). Pendidikan karakter merupakan upaya untuk membantu perkembangan jiwa anakanak baik lahir maupun batin, dari sifat kodratinya menuju ke arah peradaban manusiawi dan lebih baik (Hadi Santoso, 2019) Pendidikan karakter merupakan proses yang berlanjut dan tak pernah berakhir, sehingga menghasilkan perbaikan kualitas yang berkesinambungan yang ditunjukkan pada terwujudnya generasi yang berakar pada nilai-nilai dan budaya bangsa (Mulyana, 2018).

Dalam tujuan pendidikan karakter perlu adanya manajemen yang baik dan sinergis di antara berbagai komponen pendidikan yang terlibat baik yang bersifat formal, nonformal, maupun informal baik di sekolah, keluarga, maupun masyarakat, Pendidikan karakter di sekolah melibatkan semua komponen yang ada di sekolah tersebut, yaitu isi kurikulum proses pembelajaran dan penilaian, kualitas hubungan, penanganan dan pengelolaan mata pelajaran, pengelolaan sekola, pelaksanaan aktivitas, pemberdayaan sarana prasarana, pembiayaan, dan etos kerja seluruh warga dan lingkungan sekolah (Muhlil Musolin, 2019). Menumbuhkan siswa yang memiliki karakter yang baik bukan hal yang mudah dan cepat (Rosad, 2019). Hal tersebut membutuhkan waktu, usaha dan upaya yang dilakukan secara terus menerus serta refleksi yang mendalam untuk membuat urutan kebijakan yang harus ditindak lanjuti sehingga menjadi suatu hal yang praktis dan reflektif. Karakter yang baik terbentuk dari hati dan teruang melalui perilaku. Manajemen pendidikan karakter dilembaga pendidikan islam dimulai dari perencanaan, pengorganisasian, dan diimplikasikan dalam setiap bidang studi oleh pendidik secara bersama-sama dengan penuh tanggung jawab. Program pendidikan karakter merupakan bentuk penanaman nilai-nilai karakter yang terdiri dari keteladanan yang dilakukan oleh pendidik, pembiasaan peserta didik untuk melakukan hal-hal baik dan pemotivasian yang dilakukan oleh orang-orang yang ada di sekitar peserta didik (Baharun \& Zulfaizah, 2018). 
Program-program kegiatan di madrasah harus dilaksankan harus secara terus menerus dan berkesinambungan. Karena program-program tersebut sebagai penguat pendidikan karakter peserta didik dimasa sekarang ini (E. W Suryanti and F. D Widayanti, 2018).

MTs Raudhatul Islamiyah Kemiri sangat peduli terhadap pendidikan karakter peserta didiknya. Dengan sistem pendidikan yang islami untuk menumbuhkan karakter peserta didik yang berakhlakul karimah menjadi salah satu fokus utama yang selalu diterapkan di MTs Raudhatul Islamiyah Kemiri mengembangkan pendidikan karakter yang dibutuhkan oleh generasi pada masa ini. MTs Raudhatul Islamiyah Kemiri mengoptimalkan pengembangan karakter peserta didik melalui kegiatan-kegiatan yang dilaksanakan, baik di dalam maupun diluar jam pelajaran. Selain melalui kegiatan-kegiatannya MTs Raudhatul Islamiyah Kemiri berupaya menumbuhkan karakter peserta didiknya melalui peraturan-peraturan yang ditetapkan dan melalui muatan pelajaran keagamaannya.

\section{TINJAUAN PUSTAKA}

Manajemen menjadi sesuatu yang sangat penting demi tercapainya tujuan karakter yang efektif di suatu madrasah. Manajemen harus dilakukan secara sistematis dan konsisten melalui fungsi-fungsi manajemen. Andrew F. Sikula mengemukakan bahwa manajemen pada dasarnya dikaitkan dengan aktivitas-aktivitas perencanaan, pengorganisasian, pengendalian, penempatan, pengarahan, pemotivasian, komunikasi dan pengambilan keputusan yang dilakukan oleh setiap lembaga atau organisasi untuk mencapai tujuan secara efisien (Suwardi dan Daryanto, 2017).

Manajemen pendidikan adalah bidang studi dan praktik yang bersangkutan dengan operasi organisasi pendidikan. Manajemen pendidikan juga dapat diartikan sebagai proses untuk mencapai tujuan pendidikan dengan berbagai upaya seperti perencanaan, pengorgnisasian, pengarahan, pemantauan dan penilaian. Selain manajemen pendidikan, pendidikan karakter merupakan salah satu media yang efektif dalam aplikasi pendidikan karakter siswa di Madrasah dan sangat berkaitan dengan pengelolaan sekolah. Yang dimaksud dengan pengelolan sekolah disini adalah perencanaan, pengorganisasian, pelaksanaan, dan pengendalian dalam kegiatan-kegiatan Madrasah. Pendidikan karakter meliputi semua komponen-komponen Madrasah, yaitu isi kurikulum, proses pembelajaran dan penilaian, kualitas hubungan, penanganan dan pengelolaan mata pelajaran, pengelolaan sekolah, pelaksanaan aktivitas, pemberdayaan sarana prasarana, pembiayaan, dan etos kerja seluruh warga madrasah (Ibnu Rusydi, 2019). Semua warga madrasah mulai dari Kepala Madrasah, 
guru, staff, orang tua dan masyarakat, turut berperan serta dalam membentuk karakter siswa. Jadi, semakin baiknya manajemen pendidikan karakter di dalam Madrasah, maka akan semakin sukses juga pelaksanaan pendidikan karakter di Madrasah.

Penerapan pendidikan karakter di madrasah sangat tepat karena madrasah tidak hanya mengantar peserta didik dalam menyelesaikan tugas perkembangannya dan fokus pada prestasi-prestasi akademik yang diraih peserta didik, akan tetapi madrasah juga berperperan dalam pembentukan karakter peserta didik (Wibowo, 2018). Pembentukan karakter juga dapat diintergrasikan dalam pembelajaran pada setiap mata pelajaran. Semua normanorma atau nilai-nilai pada setiap mata pelajaran perlu dikembangkan dan kemudian diterapkan dalam kehidupan sehari-hari, baik di Madrasah maupun di lingkungan masyarakat.

\section{METODE}

Penelitian ini merupakan penelitian kualitatif yang bertujuan untuk mengetahui manajemen pendidikan yang diguanakan di tempat penelitian. Dimana penelitian dimaksudkan untuk mendeskripsikan fenomena atau gejala yang bersifat alami pada tempat yang diteliti. Teknik pengumpulan data dengan cara wawancara, observasi, dan dokumentasi. Data-data yang diperoleh dikumpulkan dan kemudian analisis disimpulkan sebagai hasil penelitian. Teknik analisis data tersebut terdiri dari pengumpulan data, reduksi data, penyajian data, dan penarikan kesimpulan (Wibowo, 2018).

\section{HASIL PEMBAHASAN}

\subsection{Isi Hasil dan Pembahasan}

Jadwal kegiatan di MTs Raudhatul Islamiyah Kemiri

\begin{tabular}{|l|l|c|l|}
\hline No & Hari & Waktu & \multicolumn{1}{c|}{ Kegiatan } \\
\hline & & $06.45-07.00$ & Asmaul Husna dan Hafalan surah Al-Qur'an \\
& & $07.00-07.55$ & Upacara bendera Merah Putih \\
& \multirow{3}{*}{ Senin } & $07.55-09.55$ & KBM \\
& & $09.55-10.10$ & Istirahat \\
& & $10.10-11.30$ & KBM \\
& & $11.30-12.10$ & Sholat berjamaah \\
& & $12.10-13.30$ & KBM \\
\hline
\end{tabular}




\begin{tabular}{|l|l|l|l|}
\hline \multirow{3}{*}{2.} & & $06.45-07.15$ & Asmaul Husna dan Hafalan surah Al-Qur'an \\
& Selasa, & $07.15-09.55$ & KBM \\
& Rabu, & $09.55-10.10$ & Istirahat \\
& Kamis, & $10.10-11.30$ & KBM \\
& Sabtu & $11.30-12.10$ & Sholat berjamaah \\
& $12.10-13.30$ & KBM \\
& & & \\
\hline 3. & Jum'at & $06.45-07.15$ & Asmaul Husna dan Hafalan surah Al-Qur'an \\
& & $07.15-09.35$ & KBM \\
& & $09.35-09.50$ & Istirahat \\
& & $09.50-11.00$ & KBM \\
\hline
\end{tabular}

Selain kegiatan-kegiatan tersebut, dalam pembentukan karakter yang berakhlakul karimah, pihak madrasah juga memberikan tata tertib kepada siswa. Terdapat pasal kewajiban dan juga pasal larangan. Pasal kewajiban diantaranya yaitu:

1) Wajib mengikuti upacara bendera setiap hari senin dan hari-hari besar lain.

2) Wajib berangkat sebelum pukul 06.45 WIB.

3) Wajib mengikuti asmaul husna dan hafalan surat Al-quran.

4) Wajib mengikuti sholat berjamaah.

5) Wajib memakai peci bagi siswa dan berjilbab bagi siswi.

6) Mengikuti pelajaran sampai akhir jam pelajaran.

7) Mengikuti kegiatan ekstrakurikuler sesuai pilihan.

8) Wajib menggunakan bahasa yang sopan dan santun kepada guru dan teman.

Pasal larangan diantaranya:

1) Dilarang merokok.

2) Dilarang membolos.

3) Menggunakan kata-kata kasar dan kotor.

4) Dilarang memakai make up yang berlebihan. 
5) Dilarang melipat lengan baju.

6) Dilarang menggunakan kaos kaki warna.

7) Dilarang pergi atau nongkrong di warung saat jam pelajaran berlangsung ataupun saat jam pelajaran kosong.

Tata tertib tersebut bertujuan untuk menumbuhkan karakteristik yang baik. Dengan selalu menaati peraturan tersebut peserta didik akan terbiasa melakukan hal-hal yang baik.

\section{KESIMPULAN}

Konsep Manajemen pendidikan karakter di MTs Raudhatul Islamiyah Kemiri, adalah sebagai berikut yang pertama: konsep yang dimaksud adalah pola menumbuhkan karakter peserta didik dengan berbagai unsur pendukung seperti kegiatan-kegiatan madrasah, tata tertib atau peraturan-peraturan di MTs Raudhatul Islamiyah Sampit. Selain unsur pendukung tersebut, dalam rangka membentuk karakter akhlakul karimah juga mempunyai beberapa strategi didalam menunjang tercapainya konsep manajemen pendidikan karakter seperti: keteladanan, pembelajaran, pemberdayaan dan pembudayaan, pengatan, dan penilaian.

\section{DAFTAR PUSTAKA}

Agus, A. H., \& Ummah, B. (2019). Strategi Image Branding Universitas Nurul Jadid Di Era Revolusi Industri 4.0. Tarbiyatuna: Jurnal Pendidikan Islam, 12(1), 59-81. Retrieved from Agustin Wahyuningtyas, U. B. W. (2017). Manajemen Pendidikan Karakter. $5(1), 33$.

Baharun, H., \& Zulfaizah. (2018). Revitalisasi pendidikan agama dalam pembentukan karakter peserta didik di madrasah. Elementary, 6(1), 46.

E. W Suryanti and F. D Widayanti. 2018. "Penguatan Pendidikan Karakter Berbasis Religius," Skripsi, no. September. Malang: FKIP, Universitas Wisnuwardhana Malang

Hadi Santoso. (2019). Implementasi Pendidikan Karakter Dalam Keluarga Muslim (Sebuah Pendekatan Sosiologis). Jurnal At-Tarbiyat: Jurnal Pendidikan Islam, 2(1), 1-24.

Ibnu Rusydi, Ali Miftakhu Rosyad, Ibnudin, Kambali, U. S. (2019). School Culture Program: Inculcating Anti- Corruption Values Through Honesty Canteen In State Elementary School: Case Study In Indramayu District, West Java, Indonesia. International Journal of Psychosocial Rehabilitation, 24(4), 5362-5378. 
Ilham, R. N., Erlina, K. A. F., Silalahi, A. S., Saputra, J., \& Albra, W. (2019). Investigation of the bitcoin effects on the country revenues via virtual tax transactions for purchasing management. Int. J Sup. Chain. Mgt Vol, 8(6), 737.

Islamic, J., \& Manajemen, E. (2019). p-ISSN: 2541-383X e-ISSN: 2541-7088. 4(2), 210.

Moch. Tohet, I. R. (2019). Penguatan Kurikulum 2013 dalam Menumbuhkan Karakter Peserta Didik di Sekolah. Jurnal At-Tarbiyat: Jurnal Pendidikan Islam, 2(2), 200-219.

Muhlil Musolin. (2019). Sadd Adz-Dzarâi’: Konsep dan Aplikasi Manajemen Pendidikan

Pendidikan Islam. Manageria, 4(1), 71-84.

Mulyasa. 2018. Manajemen Pendidikan Karakter. Jakarta: Bumi Aksara

Rosad, A. M. (2019). Implementasi Pendidikan Karakter melalui Manajemen Sekolah.

Tarbawi: Jurnal Keilmuan Manajemen Pendidikan, 5(2), 173-190.

Subaidi. (2019). Manajemen Biaya dan Sarana Prasarana di SMAN 3 Pati dan Silahul Ulum Asempapan Trangkil Pati. Jurnal At-Tarbiyat: Jurnal Pendidikan Islam, 2(1), 71-72.

Suryanti, E. W., \& Widayanti, F. D. (2018). Penguatan Pendidikan Karakter Berbasis Religius. Skripsi, (September), Malang: FKIP, Universitas Wisnuwardhana Malang.

ST Maryam, R. A., Sumartono, E., \& Dwi Orbaningsih, R. (2020). GLOBAL FINANCIAL CRISIS MANAGEMENT BY HUMAN RESOURCE MANAGEMENT. Journal of Critical Reviews, 7(1), 287-290.

Suwardi dan Daryanto. 2017. Manajemen Peserta Didik. Yogyakarta: Gava Media

Udik Budi Wibowo Agustin Wahyuningtyas. 2017. "Manajemen Pendidikan Karakter" 5, no. 1 hlm. 33

Wahid, A. H., Muali, C., \& Rafikah, K. (2018). Pengembangan Karakter Guru dalam Menghadapi Demoralisasi Siswa Perspektif Teori Dramaturgi. Jurnal Mudarrisuna, $8(1), 102-126$.

Wibowo, A. (2018). Study Komparasi Penyelenggaraan Pendidikan SMK ( Studi Kasus SMK Di Pondok Pesantren Lirboyo Al-Mahrusiyah Dan Di SMK PGRI 2. At-Tarbiyat: Jurnal Pendidikan Islam, 1(1), 1-15. 